\title{
Reply: Comment on 'KRAS and BRAF mutations are prognostic biomarkers in patients undergoing lung metastasectomy of colo-rectal cancer'
}

\author{
Stéphane Renaud ${ }^{1,2}$, Pierre-Emmanuel Falcoz ${ }^{*}, 1$, Benoit Romain ${ }^{2,3}$, Anne Olland ${ }^{1}$, Nicola Santelmo ${ }^{1}$, Cécile Brigand ${ }^{3}$, \\ Serge Rohr ${ }^{3}$, Dominique Guenot ${ }^{2}$ and Gilbert Massard ${ }^{1}$
}

${ }^{1}$ Department of Thoracic Surgery, Strasbourg University Hospital, Strasbourg, France; ${ }^{2}$ Research unit EA3430: Tumoral Progression and Microenvironnement, Translational and Epidimiological Approachs, Strasbourg University, Strasbourg, France and ${ }^{3}$ Department of General and Digestive Surgery, Strasbourg University Hospital, Strasbourg, France

Sir,

It is with great interest that we read the letter entitled 'KRAS and BRAF mutations are prognostic biomarkers in patients undergoing lung metastasectomy of colo-rectal cancer. Variation in survival associated with protooncogenes is not evidence for effectiveness of metastasectomy'.

In their comment on the prognostic value of proto-oncogenes in lung metastasectomy of colo-rectal cancer (CRC) (Renaud et al, 2015), Cardillo and colleagues stated that 'no difference in survival attributable to surgical removal of lung metastases has been shown in a control trial' and reached the conclusion on 'the doubt on effectiveness of metastasectomy in colorectal cancer' (Cardillo et al, 2015). However, as stated by the authors, no randomised controlled trial has shown a survival benefit for follow-up compared with surgery. The very large majority of the published series shows that in metastatic CRC, medical treatment alone leads to poor overall survival (OS) (Rooney et al, 2015), while surgery leads to 5-y OS up to 70\% (Riquet et al, 2010; Hawkes et al, 2012; Renaud et al, 2014).

At this point a word of caution is essential and we would like to emphasise several points that we consider to be important.

First, we agree that patients who underwent surgery were highly selected. However, the proper selection of candidates for surgery is the basis of surgical oncology. As an example, stereotactic ablative radiotherapy and radiofrequency are offered as alternatives to surgery in resectable NSCLC unfit for surgery, since poor medical condition is associated with worse outcomes (Boily et al, 2015; Dupuy et al, 2015). Consequently, the doubt of hyperselection can be applied to all the fields of surgical oncology.

Second, the authors relevantly stated that 'the study shows the influence of oncogenes on survival but these are likely to be general prognostic factors'. They are right! Our aim was to identify new prognostic factors. Indeed, despite known prognostic factors, there are wide variations of OS among patients after metastasectomy of CRC. It seems that, from the primary CRC tumour, the molecular status could predict the course and the aggressivity of CRC (Renaud et al, 2015). Consequently, molecular markers might help to a better selection of patients, from the primary CRC surgery. In addition, we further think that molecular analysis could be even more helpful. Indeed, it seems that KRAS specific amino-acid substitutions is associated with different activations of downstream effectors, which can induce different behaviours (Garassino et al, 2011; Ihle et al, 2012; Izar et al, 2014; Nadal et al, 2014). In particular, in CRC cell lines, KRAS G12V is known to overexpress CXCR4, implied in metastasis process, promoting higher aggressivity (Alamo et al, 2015). These interesting preliminary results may lead in the future to a molecular prognostic classification, which may help to select the best patients for surgery.

Third, in the meta-analysis of Gonzalez et al (2013), CEA remained significant in multivariate analysis in only 9 out of 19 selected studies. Furthermore, CEA only reflects the total tumour mass. On the other hand, the absence of impact of disease free survival in our work probably reflects the proper selection of patients.

Fourth, meta-analyses cited by the authors, such as the latest one, does not add supplementary reflexion to our discussion (Gonzalez et al, 2013). Indeed, it only identifies four risk factors of poor outcome, which have been included in our analysis.

Fifth, CEA second look trial recruited patients who were randomised between surgery and follow-up according only to CEA elevation (Treasure et al, 2014). Obviously, this study cannot be generalised to lung metastasectomy of CRC: (1) patients with extra-abdominal recurrence were excluded, and different regimen of peri-operative treatment were used; (2) the use of CEA alone may have probably led to the inclusion of patients without recurrence, for whom surgery was futile. Indeed, patients were included in case of CEA $>10 \mathrm{ng} \mathrm{ml}^{-1}$. However, when $<30 \mathrm{ng} \mathrm{ml}^{-1}$, many conditions can induce CEA increase, in particular smoking and alcohol. Excluding these conditions by simple questioning exposed to information biases. Otherwise, Primrose et al (2014) did not reach the conclusion that treatment of recurrence was unnecessary, but that intensive follow-up after surgery, even if detecting earlier recurrence, does not significantly diminish the mortality in comparison with minimum follow-up (Primrose et al, 2014). Furthermore, they clearly stated that 'detection of recurrence that was treatable surgically with curative intent was chosen as the main outcome measure' (Primrose et al, 2014), and 'that the statistical power of their trial to assess a mortality advantage of intensive follow-up was limited' (Mant and Primrose, 2014). Finally, in their work, recurrence was treated by various regimen forbidding to conclude on the benefit of surgical treatment of recurrence.

Consequently, so far, we strongly advocate that no data allows concluding that lung metastasectomy is a futile procedure in CRC.

\section{CONFLICT OF INTEREST}

The authors declare no conflict of interest.

\section{REFERENCES}

Alamo P, Gallardo A, Di Nicolantonio F, Pavon MA, Casanova I, Trias M, Mangues MA, Lopez-Pousa A, Villaverde A, Vazquez E, Bardelli A, Cespedes MV, Mangues R (2015) Higher metastatic efficiency of KRas G12V than KRas G13D in a colorectal cancer model. FASEB J 29(2): 464-476.

Boily G, Filion E, Rakovich G, Kopek N, Tremblay L, Samson B, Goulet S, Roy I (2015) Stereotactic ablative radiation therapy for the treatment of early-stage non-small-cell lung cancer: CEPO review and recommendations. J Thorac Oncol 10(6): 872-882.

Cardillo G, Mokhles S, Williams N, Macbeth F, Russell C, Treasure T (2015) KRAS and BRAF mutations are prognostic biomarkers in patients undergoing lung metastasectomy of colorectal cancer. Variation in survival associated with proto-oncongenes is not evidence for effectiveness of lung metastasectomy. $\mathrm{Br} J$ Cancer 113(11): 1636.

Dupuy DE, Fernando HC, Hillman S, Ng T, Tan AD, Sharma A, Rilling WS, Hong K, Putnam JB (2015) Radiofrequency ablation of stage IA non-small cell lung cancer in medically inoperable patients: results from the American College of Surgeons Oncology Group Z4033 (Alliance) trial. Cancer; e-pub ahead of print 19 June 2015; doi:10.1002/cncr.29507.

Garassino MC, Marabese M, Rusconi P, Rulli E, Martelli O, Farina G, Scanni A, Broggini M (2011) Different types of K-Ras mutations could affect drug sensitivity and tumour behaviour in non-small-cell lung cancer. Ann Oncol 22(1): 235-237.

Gonzalez M, Poncet A, Combescure C, Robert J, Ris HB, Gervaz P (2013) Risk factors for survival after lung metastasectomy in colorectal cancer patients: a systematic review and meta-analysis. Ann Surg Oncol 20(2): 572-579.

Hawkes EA, Ladas G, Cunningham D, Nicholson AG, Wassilew K, Barbachano Y, Ratnayake G, Rao S, Chau I (2012) Peri-operative chemotherapy in the management of resectable colorectal cancer pulmonary metastases. $B M C$ Cancer 12: 326.

Ihle NT, Byers LA, Kim ES, Saintigny P, Lee JJ, Blumenschein GR, Tsao A, Liu S, Larsen JE, Wang J, Diao L, Coombes KR, Chen L, Zhang S, Abdelmelek MF, Tang X, Papadimitrakopoulou V, Minna JD, Lippman SM, Hong WK, Herbst RS, Wistuba, Heymach JV, Powis G (2012) Effect of KRAS oncogene substitutions on protein behavior: implications for signaling and clinical outcome. J Natl Cancer Inst 104(3): 228-239.

Izar B, Zhou H, Heist RS, Azzoli CG, Muzikansky A, Scribner EE, Bernardo LA, Dias-Santagata D, Iafrate AJ, Lanuti M (2014) The prognostic impact of KRAS, its codon and amino acid specific mutations, on survival in resected stage I lung adenocarcinoma. J Thorac Oncol 9(9): 1363-1369.

Mant D, Primrose J (2014) CEA monitoring in colorectal cancer is not a waste of time. $B M J$ 348: g4032.

Nadal E, Chen G, Prensner JR, Shiratsuchi H, Sam C, Zhao L, Kalemkerian GP, Brenner D, Lin J, Reddy RM, Chang AC, Capella G, Cardenal F, Beer DG, Ramnath N (2014) KRAS-G12C mutation is associated with poor outcome in surgically resected lung adenocarcinoma. J Thorac Oncol 9(10): $1513-1522$.

Primrose JN, Perera R, Gray A, Rose P, Fuller A, Corkhill A, George S, Mant D (2014) Effect of 3 to 5 years of scheduled CEA and CT follow-up to detect recurrence of colorectal cancer: the FACS randomized clinical trial. JAMA 311(3): 263-270.

Renaud S, Alifano M, Falcoz PE, Magdeleinat P, Santelmo N, Pages O, Massard G, Regnard JF (2014) Does nodal status influence survival? Results of a 19-year systematic lymphadenectomy experience during lung metastasectomy of colorectal cancer. Interact Cardiovasc Thorac Surg 18(4): $482-70$.

Renaud S, Romain B, Falcoz PE, Olland A, Santelmo N, Brigand C, Rohr S, Guenot D, Massard G (2015) KRAS and BRAF mutations are prognostic biomarkers in patients undergoing lung metastasectomy of colorectal cancer. BrJ Cancer 112(4): $720-780$. 
Riquet M, Foucault C, Cazes A, Mitry E, Dujon A, Le Pimpec Barthes F, Medioni J, Rougier P (2010) Pulmonary resection for metastases of colorectal adenocarcinoma. Ann Thorac Surg 89(2): 375-380.

Rooney KP, McAleese J, Crockett C, Harney J, Eakin RL, Young VA, Dunn MA, Johnston RE, Hanna GG (2015) The impact of colleague peer review on the radiotherapy treatment planning process in the radical treatment of lung cancer. Clin Oncol ( $R$ Coll Radiol) 27(9): 514-580.

Treasure T, Monson K, Fiorentino F, Russell C (2014) The CEA second-look trial: a randomised controlled trial of carcinoembryonic antigen prompted reoperation for recurrent colorectal cancer. BMJ Open 4(5): e004385.

*Correspondence: Professor P-E Falcoz; E-mail: pierre-emmanuel.falcoz@wanadoo.fr Published online 15 September 2015

(c) 2015 Cancer Research UK. All rights reserved 0007-0920/15

http://creativecommons.org/licenses/by-nc-sa/4.0/

\section{Is it the creatine or the anabolic androgenic steroids? Need for assessing the steroids role in testicular cancer}

Patrick Cazorla-Saravia ${ }^{*}, 1$ and Reneé Pereyra-Elías ${ }^{1}$

${ }^{1}$ MD Escuela de medicina, Universidad Peruana de Ciencias Aplicadas,

Sir,

We have read with considerable interest the case-control study by Li et al. (2015), in which muscle building supplement (MBS) use was found as an associated factor with testicular germ cell cancer. It is important to remark that the association remained statistically significant even after controlling for important potential confounders. However, we consider that there is one nonassessed variable that might be relevant in the multi-causal model for testicular cancer.

Previous research shows that the frequency of anabolic androgenic steroid (AAS) use within practitioners of recreational physical activity can be as high as 30 (Abrahin et al, 2014) to 50\% (Dodge et al, 2011). Therefore, there is high probability of concomitant AAS and MBS use. In addition, AASs have been associated with the development of some types of cancer. Nandrolone and stanozolol, two of the most used AASs, have proven to enhance Leydig cell proliferation, increasing the risk of tumour development in rats (Chimento et al, 2012). There is also suggestive evidence that involves AAS in Leydig cell tumour growth in humans (Belli et al, 2013). In this scenario, AAS could be playing an undetected role in malignancy development instead of or in conjunction with MBS.

Moreover, two recently published articles detected the presence of AAS in products marketed as dietary supplements (Abbate et al, 2014; Odoardi et al, 2015). Thus, the MBS consumed by Li's study participants could have been contaminated with AAS. This highly probable mix of substances does not allow us to convincingly blame one specific compound.

In summary, Li's results provide valuable information suggestive of MBS use as a potential risk factor for testicular cancer. However, future research

Calle El Paraíso 170, La Molina, Lima 12, Peru

considering the potential AAS effect should be carried out in order to clarify the real influence of this substance.

\section{REFERENCES}

Abbate V, Kicman AT, Evans-Brown M, McVeigh J, Cowan DA, Wilson C, Coles SJ, Walker CJ (2014) Anabolic steroids detected in bodybuilding dietary supplements - a significant risk to public health. Drug Test Anal 7: 609-618.

Abrahin OS, Sousa EC, Santos AM (2014) Prevalence of the use of anabolicandrogenic steroids in Brazil: a systematic review. Subst Use Misuse 49(9): $1156-1162$.

Belli S, Guidi A, Simoni M, Carani C, Granata AR (2013) Leydig cell tumor in an anabolic steroid abuser. J Endocrinol Invest 36(10): 913.

Chimento A, Sirianni R, Zolea, De Luca A, Lanzino M, Catalano S, Ando S, Pezzi V (2012) Nandrolone and stanozolol induce Leydig cell tumor proliferation through an estrogen-dependent mechanism involving IGF-I system. J Cell Physiol 227: 2079-2088.

Dodge T, Hoagland MF (2011) The use of anabolic androgenic steroids and polypharmacy: a review of the literature. Drug Alcohol Depend 114: $100-109$

Li N, Hauser R, Holford T, Zhu Y, Zhang Y, Bassig BA, Honig S, Chen C, Boyle P, Dai M, Schwartz SM, Morey P, Sayward H, Hu Z, Shen H, Gomery P, Zheng T (2015) Muscle-building supplement use and increased risk of testicular germ cell cancer in men from Connecticut and Massachusetts. Br J Cancer 112: $1247-1250$.

Odoardi S, Castrignanò E, Martello S, Chiarotti M, Strano-Rossi S (2015) Determination of anabolic agents in dietary supplements by liquid chromatography-high-resolution mass spectrometry. Food Addit Contam Part A Chem Anal Control Expo Risk Assess 32(5): 635-647.

*Correspondence: Dr P Cazorla-Saravia; E-mail: patrickcazorla@hotmail.com Published online 11 August 2015

(c) 2015 Cancer Research UK. All rights reserved 0007-0920/15
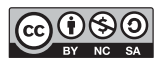

http://creativecommons.org/licenses/by-nc-sa/4.0/
$\mathrm{BJC}$ OPEN 1

\section{Comment on 'Impact of intra-arterial chemotherapy including internal carotid artery for advanced paranasal sinus cancers involving the skull base'}

Paolo Bossi ${ }^{*, 1}$, Ester Orlandi ${ }^{1}$ and Lisa Licitra ${ }^{1}$

${ }^{1}$ Fondazione IRCCS Istituto Nazionale dei Tumori, Milan, Head and Neck Medical Oncology Unit, Via Venezian, 1, Milano, Italy

Sir,

We read with great interest the paper by Yokoyama J et al, 2014. 'Impact of intra-arterial chemotherapy including internal carotid artery for advanced paranasal sinus cancers involving the skull base'.

There are some major issues that in our opinion strongly limit the possibility of drawing any conclusions.

The paper presents the experience of intra-arterial cisplatin chemotherapy (46 patients) compared with historical controls (11 patients) not employing infusion of the internal carotid artery, presenting survival data of both series. However, it is difficult to make any comparison, as there is no histology specification about the treated cancers, which can have a significant prognostic impact in paranasal sinus cancers (Ganly et al, 2005; Llorente et al, 2014).

The inclusion criteria of this study have not been specified. For example, it is unclear how many patients were considered and how many were eligible; this would help in understanding the feasibility of this approach. How many cases were judged as unresectable? This is the group of patients having the worst prognosis, which indeed would benefit from alternative approaches such as intra-arterial chemotherapy (Hoppe et al, 2008); on the other hand, when a paranasal sinus cancer is resectable, surgery represents the standard treatment followed by radiotherapy (Dulguerov and Allal, 2006).

Moreover, it is very unclear if the adopted therapeutic strategy was the same for all cases. The authors stated that 29 of 32 patients with invasion of orbital apex were treated with preservation of the orbital contents, probably suggesting that radiotherapy was given in a preoperative setting.

Therefore, it is vital to clarify whether radiotherapy was administered with radical intent or preoperatively. The reported total dose of $60 \mathrm{~Gy}$ to tumour and nodal metastasis with standard fractionation could hardly be curative if definitive treatment was planned. In fact, receiving a total dose of at least $65 \mathrm{~Gy}$ is known to be a significant prognostic factor for both tumour local control and overall survival at least in unresectable paranasal sinus cancers (Hoppe et al, 2008). Furthermore, no specific data on surgery has been provided in the paper.

In the statistical part, larynx-preservation rates are calculated and compared between the two groups. In our experience larynx preservation is 